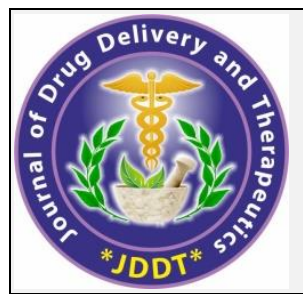

Available online on 15.12.2020 at http://jddtonline.info Journal of Drug Delivery and Therapeutics

Open Access to Pharmaceutical and Medical Research

(C) 2011-18, publisher and licensee JDDT, This is an Open Access article which permits unrestricted non-commercial use(CC By-NC), provided the original work is properly cited

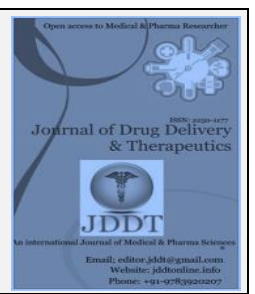

Open Access

Review Article

\title{
Assessment of Modern Excipients in Controlled Delivery of Proteins and Peptides
}

\author{
Robertina Calico ${ }^{1}$, Venkata Sai Dheeraj Munjulury*2 \\ ${ }^{1}$ Department of Polymer Science, University of Bologna, 40126 Bologna, Italy \\ 2 Department of Formulation R\&D, Cipla Ltd., 400083, Mumbai, India
}

\begin{abstract}
Polymeric micelles are highly proficient of modulating the function, distribution of drugs in the body, and can overcome biological barriers hence provoked as novel nanomedicine via various formulations. Current review emphasis on application of several polymers, biomaterials, lipids for the preparation of polymeric micelles formed by several molecular interactions between the block co-polymers and encapsulated molecules. Micellar carriers will be selected on basis of the type of polymer/payload interaction, which includes biological interface focused on the internal chemistry and fabrication of block-co polymers. Several features of these carriers can be manipulated to catering a broad range of drugs through active sensing of body targets. The fine-tuning of their properties in response to particular stimuli, modulating the activity of the loaded drugs at the targeted sites, even at the subcellular level. To end with, the future perspective and impending challenges for polymeric micelles as nanomedicine are elaborated, anticipating prompting further innovations.
\end{abstract}

Keywords: Proteins, Peptides, Co-block Polymers, Lipids, Controlled, Drug Delivery.

Article Info: Received 03 Oct 2020; $\quad$ Review Completed 21 Nov 2020; $\quad$ Accepted 29 Nov 2020; $\quad$ Available online 15 Dec 2020

Cite this article as:

Calico R, Munjulury VSD, Assessment of Modern Excipients in Controlled Delivery of Proteins and Peptides, Journal of Drug Delivery and Therapeutics. 2020; 10(6-s):134-138 http://dx.doi.org/10.22270/jddt.v10i6-s.4631

*Address for Correspondence:

Venkata Sai Dheeraj Munjulury, Cipla Ltd., IPD-R\&D, LBS Marg, Vikhroli(W), Mumbai 400083, India

\section{Introduction}

Several pharmaceutical and biotechnology companies are focusing on the development of several new proteins and peptide-based compounds for treating a wide range of diseases. This was further supported by rapid advancement in the biotechnology and genome research fields. But, conversely, these new compounds are larger, hydrophilic, and relatively unstable in contrast with the traditional active moieties. All these features make them ineffective for permeation across biological barriers and enzymatic degradation, consequently, peptides and proteins are very difficult to deliver by conventional pathways like oral or transdermal, or nasal ${ }^{1-4}$.

Owing to adsorption and low bioavailability through these routes, proteins and peptides are administered preferably by intramuscular or subcutaneous injection. However, half-lives of these proteins are only several minutes of a few hours, when administered parenterally, thus require frequent dosing for optimum therapeutic efficacy. Extensive research has been performed to overall the above issues discussed. Controlled release systems are one amongst them, to obtain the well-defined pharmacokinetic profile. One promising approach is to encapsulate the peptides or proteins in a polymer matrix, to protect them from degradation and rapid clearance thus prolongs the release of the drug 5-10. A broad range of degradable and non-degradable polymers have been used as matrices to incorporate several drugs. Several carriers like nanocrystals, nanoparticles, ethosomes, have been formulated 10-13. Among all these biodegradable polymers are preferred to avoid further surgical removal of the matrix after depletion of the drug from the system. The continuous release of drugs from the biodegradable polymer matrix could occur either by diffusion of the drug from the matrix or by the degradation of the polymer or by a combination of the two mechanisms.

Yet, a major concern for these systems is biocompatibility, the stability of encapsulated moieties during processing, release, and storage. Despite these challenges, several controlled-release formulations were approved and marketed. As shown below, the polymer matrix can be formulated either as nanospheres, microspheres, injectable gel, or implant. Spheres and gels are most recommended over the implants, as no surgical procedure for administration is required. List of controlled release systems formulated on basis of biodegradable polymers ${ }^{14-20}$ [Table $1]$. 
Table 1: List of controlled release systems and their application, formulated with biodegradable polymers

\begin{tabular}{|c|l|l|}
\hline S. No & Product & Application \\
\hline 1. & Atridox® Doxycycline PLA gel & Periodontal disease \\
\hline 2. & Gliadel® Carmustin Polyanhydride wafer & Brain cancer \\
\hline 3. & Lupron Depot@ Leuprolide acetate PLGA microspheres & Prostate cancer \\
\hline 4. & Nutropin Depot@ Somatropin PLGA microspheres & Growth hormone deficiency \\
\hline 5. & Sandostatin LAR® Octreotide acetate PLGA-glucose microspheres & Growth hormone suppression \\
\hline 6. & TrelstarTM Depot Triptorelin PLGA microspheres & Prostate cancer \\
\hline 7. & Zoladex® Goserelin acetate PLGA rod & Prostate cancer \\
\hline
\end{tabular}

\section{Biodegradable polymer matrices for controlled release:}

The polymer should satisfy several criteria's such as biocompatible, degradable within a reasonable period (depending on application), and the non-toxic degradation products, to use as a drug delivery matrix. Additionally, the polymer should be able to provide an optimum environment for the encapsulated protein or peptide drug, to prevent denaturation, which may cause unwanted immunogenicity when administered. The release rate of the drug can be tailored by modifying the polymer characteristics to obtain optimal therapeutic efficacy. Several works have focused on poly(lactic-co-glycolic acid) (PLGA) copolymers. These polymers are in use for several decades as surgical suture materials and are known for their excellent biocompatible nature 21-25. Their degradation is by Kreb's cycle to carbon dioxide and water. Despite the success with small peptides, such as luteinizing hormone-releasing analogues, there is considerable concern about the suitability of PLGA as a polymeric carrier for high molecular weight protein drugs ${ }^{26-}$ 28.

Protein unfolding and aggregation often occurs during the storage or release, because of the interaction of protein molecules with the hydrophobic polymeric surface. Moreover, the low $\mathrm{pH}$ generated during polymer degradation could cause chemical degradation of entrapped proteins. Another major issue with these PLGA matrices is, limited possibilities to manipulate the protein release rate and frequently, the initial burst has been noticed from these matrices to result in the plateau of incomplete drug release 29-32. Hence to overcome these issues, Amphiphilic block copolymers have gained increasing interest for drug delivery applications $32-36$.

Introducing hydrophilic or hydrophobic blocks, a protein friendly environment can be created with modified drug release properties. In recent times, series of poly(etherester) multiblock copolymers composed of repeating blocks of hydrophilic poly(ethylene glycol)-terephthalate (PEGT) and hydrophobic poly(butylene terephthalate) (PBT) was introduced as a matrix for controlled release systems $37-40$. This multi-block polymer is currently applied for a broad range of pharmaceutical and biomedical applications, including FDA approved products Proliposomes, Microparticles, Solid lipid Nanoparticles, Nanoparticles, 41-43. Several in-vitro and in-vivo studies have shown that PEGT/PBT copolymers are biocompatible and can be made biodegradable 44-48. Quantitative in-vitro release of fully active lysozyme has been reported from these multiblock copolymers for Nanoemulsion, Nanocrystals, Nanowires, Self-nano emulsifying drug delivery system (SNEDDS) 49-52. The controlled release of proteins for a longer period can be obtained by combining diffusion and degradation mechanisms. Additionally, various copolymer compositions could precisely modulate the release.

\section{Biodegradable multiblock copolymers for protein delivery applications}

The primary drawback of nucleic acids for pharmaceutical application is their inclination to enzymatic degradation in biological fluids. When mixed with plasma, naturally occurring nucleic acids get digest immediately and various strategies have been applied since the beginning to overcome the aforesaid issue. These are majorly divided into two approaches; one is a chemical modification of nucleotide backbone. A variety of chemically modified nucleotide backbones, including phosphorothioate, 2'-Omethylated ribose, and "locked (or bridged)" nucleotides, have been prepared to enhance the stability of nucleic acids, and some of them are used are clinically approved. The details in chemical modification approaches are elaborated by several researchers using Chitosan, Alginate, PLGA, Polyvinylpyrrolidone (PVP), Zein, Okra, 53-58. Another approach is the encapsulation of nucleic acids within nanoparticulate formulations, such as PIC micelles. With this approach, nucleic acids can be protected from external stimuli as well as enzymatic degradation, leading to their longevity in biological fluids. Certainly, several cationic lipids and polymers have been employed for the preparation of PICs, polyplex, and termed lipoplex respectively, especially with negative charged nucleic acids. Predominantly, PIC micelles have been measured as one of the most capable systems for systemic oligonucleotide delivery because of the above-mentioned properties suitable for stable circulation in the bloodstream 59-62. Oligonucleotide delivery further needs cautious design criteria for block copolymers and their assembly, owing to their inefficient cellular uptake and fragility of naked oligonucleotides.

Oligonucleotide delivery needs contradictory functions such as stable encapsulation and stealthiness in the systemic circulation for translocation into cytoplasm and endosome. A classy approach for the merging of these conflicting necessities is the creation of smart PIC micelles that use the desired function in the response to specific biological signals. The consecutive sections describe the prominent strategies to develop such PIC micelles directed to successful delivery using Hyaluronic Acid 63-65. Stabilizing the systems can be done by using reversible cross-linking of the micellar core. Disulfide crosslinking has been considered as the most extensively explored mechanism, because of preferable diffusion into reductive cytoplasm having higher concentrations of glutathione. Accordingly, disulfide crosslinked PIC micelles loading siRNA showed a certain level of stability in serum having media and capable of enhancing 
gene silencing in the cultured cells. On the other hand, still, their half-life was not considerably prolonged in comparison to non-cross-linked control micelles, probably due to leakage of siRNA payloads from the cross-linking network in the systemic circulation. The cross-linking approach can be combined with the hydrophobic stabilization using cholesterol-modified siRNA (Chol-siRNA), that is, CholsiRNA-loaded/disulfide cross-linked PIC micelles, which extensively improved the blood circulation 66-68. In the meantime, all these results suggest the direct covalent conjugation of siRNA with catiomer segment via reversible bonds. Thiol functionality to both siRNA and catiomer segment can be done by disulfide bond. Alternatively, another approach is using natural siRNA structure for covalent conjugation with catiomer segments. Therefore, natural siRNA loaded in these micelles works as a crosslinker between PBA-functionalized segments 69-70. Potential triggers for siRNA release from PIC micelles can happen through ligand exchange reaction and fluids containing cisdiol compounds. PBA-micelles were stable at blood levels of glucose $(5 \mathrm{mM})$ and ATP $(0.5 \mathrm{mM})$. They will release siRNA in the presence of intracellular levels of ATP, thus allowing the selective cytosolic release of siRNA 71-74. These outcomes also suggest that the negative charges derived from triphosphate of ATP may be critical for the trigger release of siRNA from micelles and micelle destabilization.

\section{Conclusion}

Unique properties of peptide block copolymers make them unique carriers when compared to synthetic block copolymers. To bring these materials into the application, an in-depth understanding of the interplay between composition, assembly behavior and other physicochemical properties is essential. In this review, concise trends in protein building block design approach for preparation, characterization techniques, and potential applications were discussed. Recombinant technology has become a functional approach to engineer protein-based block polymers, as it provides advantages to various fields of biomaterials. Conjugation of a peptide block with a synthetic block results in the formation of novel biomaterials with advanced functions. Furthermore, the formulation of several novel biomaterials has become possible by applying the concept of polymer engineering. Biological peptides possess admirable building blocks from which materials desired functionality, structure, and architecture can be constructed. Biomaterials with programmed structures and functions can be made with the conjugation of peptide blocks with synthetic or biological blocks. Despite many thriving examples discussed here, functionality has begun receiving attention and the roles remain to be explored. Still, there are many challenges and opportunities to employ the concepts from nature and polymer science to adopt several suitable functional materials for a wide range of applications.

\section{References:}

1. Bromberg LE, Ron ES. Temperature-responsive gels and thermogelling polymer matrices for protein and peptide delivery. Advanced drug delivery reviews. 1998 May 4; 31(3):197-221.

2. Abdelhady, S., Honsy, K. M., \& Kurakula, M. Electro SpunNanofibrous Mats: A Modern Wound Dressing Matrix with a Potential of Drug Delivery and Therapeutics. Journal of Engineered Fibers and Fabrics, 2015; 10(4):155892501501000. https://doi.org/10.1177/155892501501000411

3. Lv J, Tan E, Wang Y, Fan Q, Yu J, Cheng Y. Tailoring guanidyl-rich polymers for efficient cytosolic protein delivery. Journal of Controlled Release. 2020 Apr 10;320:412-20.

4. Ahmed, O. A. A., Kurakula, M., Banjar, Z. M., Afouna, M. I., \& Zidan, A. S. Quality by design coupled with near infrared in formulation of transdermal glimepiride liposomal films. Journal of Pharmaceutical Sciences, 2015; 104(6):2062-2075. https://doi.org/10.1002/jps. 24448

5. Alhakamy, N. A., Ahmed, O. A. A., Kurakula, M., Caruso, G., Caraci, F., Asfour, H. Z., Alfarsi, A., Eid, B. G., Mohamed, A. I., Alruwaili, N. K., Abdulaal, W. H., Fahmy, U. A., Alhadrami, H. A., Eldakhakhny, B. M., \& Abdel-Naim, A. B. Chitosan-based microparticles enhance ellagic acid's colon targeting and proapoptotic activity. $\begin{array}{lll}\text { Pharmaceutics, } & \text { 2020; } 2(7): 1-14 .\end{array}$ https://doi.org/10.3390/pharmaceutics12070652

6. Lv J, Tan E, Wang Y, Fan Q, Yu J, Cheng Y. Tailoring guanidyl-rich polymers for efficient cytosolic protein delivery. Journal of Controlled Release. 2020 Apr 10;320:412-20.

7. Asfour MH. Advanced trends in protein and peptide drug delivery: a special emphasis on aquasomes and microneedles techniques. Drug Delivery and Translational Research. $2020 \mathrm{Apr}$ 26:1-23.

8. Alhakamy, N. A., Fahmy, U. A., Ahmed, O. A. A., Caruso, G., Caraci, F., Asfour, H. Z., Bakhrebah, M. A., Alomary, M. N., Abdulaal, W. H., Okbazghi, S. Z., Abdel-Naim, A. B., Eid, B. G., Aldawsari, H. M., Kurakula, M., \& Mohamed, A. I. Chitosan coated microparticles enhance simvastatin colon targeting and pro-apoptotic activity. $\begin{array}{llr}\text { Marine } & \text { Drugs, } & \text { 2020; }\end{array}$ https://doi.org/10.3390/md18040226

9. Messina KM. Polymeric Materials to Improve the Stability and Delivery of Insulin and Glucagon (Doctoral dissertation, UCLA).

10. Hasnain, M. S., Kiran, V., Kurakula, M., Rao, G. K., Tabish, M., \& Nayak, A. K. Use of alginates for drug delivery in dentistry. In Alginates in Drug Delivery (2020; pp. 387-404). Elsevier. https://doi.org/10.1016/b978-0-12-817640-5.00015-7

11. $\mathrm{Wu} \mathrm{C}, \mathrm{Mu} \mathrm{H}$. Lipid and PLGA Microparticles for Sustained Delivery of Protein and Peptide Drugs. Pharmaceutical Nanotechnology. 2020 Feb 1; 8(1):22-32.

12. Hasnain, M. S., Nayak, A. K., Kurakula, M., \& Hoda, M. N. Alginate nanoparticles in drug delivery. In Alginates in Drug Delivery (2020; pp. 129-152). Elsevier. https://doi.org/10.1016/b9780-12-817640-5.00006-6

13. Lee YW, Luther DC, Goswami R, Jeon T, Clark V, Elia J, Gopalakrishnan S, Rotello VM. Direct cytosolic delivery of proteins through coengineering of proteins and polymeric delivery vehicles. Journal of the American Chemical Society. 2020 Feb 12; 142(9):4349-55.

14. Hosny, K. M., Aldawsari, H. M., Bahmdan, R. H., Sindi, A. M., Kurakula, M., Alrobaian, M. M., Aldryhim, A. Y., Alkhalidi, H. M., Bahmdan, H. H., Khallaf, R. A., \& El Sisi, A. M. Preparation, Optimization, and Evaluation of Hyaluronic Acid-Based Hydrogel Loaded with Miconazole Self-Nanoemulsion for the Treatment of Oral Thrush. AAPS PharmSciTech, 2019; 20(7):297. https://doi.org/10.1208/s12249-019-1496-7

15. Wang Y, Zhang W, Gong C, Liu B, Li Y, Wang L, Su Z, Wei G. Recent advances in the fabrication, functionalization, and bioapplications of peptide hydrogels. Soft Matter. 2020; 16(44):10029-45.

16. Kurakula, M., \& A. Ahmed, T. Co-Delivery of Atorvastatin Nanocrystals in PLGA based in situ Gel for Anti-Hyperlipidemic Efficacy. Current Drug Delivery, 2015; 13(2):211-220. https://doi.org/10.2174/1567201813666151109102718

17. Wang Y, Zhang W, Gong C, Liu B, Li Y, Wang L, Su Z, Wei G. Recent advances in the fabrication, functionalization, and bioapplications of peptide hydrogels. Soft Matter. 2020; 16(44):10029-45.

18. Kurakula, M., Ahmed, O. A. A., Fahmy, U. A., \& Ahmed, T. A. Solid lipid nanoparticles for transdermal delivery of avanafil: optimization, formulation, in-vitro and ex-vivo studies. Journal of Liposome Research, 2016; 26(4):288-296. https://doi.org/10.3109/08982104.2015.1117490

19. Asadzadeh H, Moosavi A, Arghavani JH. The effect of chitosan and PEG polymers on stabilization of GF-17 structure: A molecular dynamics study. Carbohydrate Polymers. 2020 Mar 7:116124.

20. Kurakula, M., El-Helw, A. M., Sobahi, T. R., \& Abdelaal, M. Y. Chitosan based atorvastatin nanocrystals: Effect of cationic charge on particle size, formulation stability, and in-vivo efficacy. International Journal of Nanomedicine, 2015; 10:321334. https://doi.org/10.2147/IJN.S77731

21. Mondal S, Das S, Nandi AK. A review on recent advances in polymer and peptide hydrogels. Soft Matter. 2020; 16(6):140454.

22. Das SS, Bharadwaj P, Bilal M, Barani M, Rahdar A, Taboada P, 
Bungau S, Kyzas GZ. Stimuli-responsive polymeric nanocarriers for drug delivery, imaging, and theragnosis. Polymers. 2020 Jun; 12(6):1397.

23. Kurakula, M., \& Koteswara Rao, G. S. N. Moving polyvinyl pyrrolidone electrospun nanofibers and bioprinted scaffolds toward multidisciplinary biomedical applications. European Polymer Journal, 2020; 136:109919. https://doi.org/10.1016/j.eurpolymj.2020.109919

24. Lv J, Liu C, Lv K, Wang H, Cheng Y. Boronic acid-rich dendrimer for efficient intracellular peptide delivery. Science China Materials. 2020 Apr; 63(4):620-8.

25. Kavand A, Anton N, Vandamme T, Serra CA, Chan-Seng D. Synthesis and functionalization of hyperbranched polymers for targeted drug delivery. Journal of Controlled Release. 2020 May 10; 321:285-311.

26. Kurakula, M., Naveen, N. R., \& Yadav, K. S. Formulations for Polymer Coatings. Polymer Coatings, 2020; 415-443. https://doi.org/10.1002/9781119655145.ch19

27. Bukchin A, Sanchez-Navarro M, Carrera A, Teixidó M, Carcaboso AM, Giralt E, Sosnik A. Amphiphilic Polymeric Nanoparticles Modified with a Retro-Enantio Peptide Shuttle Target the Brain of Mice. Chemistry of Materials. 2020 Aug 24; 32(18):7679-93.

28. Kurakula, M., \& Raghavendra Naveen, N. In situ gel loaded with chitosan-coated simvastatin nanoparticles: Promising delivery for effective anti-proliferative activity against tongue carcinoma. Marine Drugs, 2020; 18(4):201. https://doi.org/10.3390/md18040201

29. Mukhopadhyay S, Prasad AB, Mehta $\mathrm{CH}$, Nayak UY. Antimicrobial peptide polymers: No escape to ESKAPE pathogens-A review. World Journal of Microbiology and Biotechnology. 2020 Sep; 36(9):1-4.

30. Ke L, Cai P, Wu YL, Chen X. Polymeric nonviral gene delivery systems for cancer immunotherapy. Advanced Therapeutics. 2020 Jun; 3(6):1900213.

31. Kurakula, M., Rao, G. K., Kiran, V., Hasnain, M. S., \& Nayak, A. K. Alginate-based hydrogel systems for drug releasing in wound healing. In Alginates in Drug Delivery (2020; pp. 323-358) Elsevier. https://doi.org/10.1016/b978-0-12-817640-5.000133

32. Albuquerque T, Faria R, Sousa Â, Neves AR, Queiroz JA, Costa D. Polymer-peptide ternary systems as a tool to improve the properties of plasmid DNA vectors in gene delivery. Journal of Molecular Liquids. 2020 Apr 17:113157.

33. Rao, G. S. N. K., Kurakula, M., \& Yadav, K. S. Application of Electrospun Materials in Gene Delivery. Electrospun Materials and Their Allied Applications, 2020; 265-306

34. Bolu BS, Golba B, Sanyal A, Sanyal R. Trastuzumab targeted micellar delivery of docetaxel using dendron-polymer conjugates. Biomaterials Science. 2020; 8(9):2600-10.

35. Ferguson EL, Varache M, Stokniene J, Thomas DW. Polysaccharides for protein and peptide conjugation. InPolymer-Protein Conjugates 2020 Jan 1 (pp. 421-453). Elsevier.

36. Kurakula, M., \& Rao, G. S. N. K. Pharmaceutical assessment of polyvinylpyrrolidone (PVP): As excipient from conventional to controlled delivery systems with a spotlight on COVID-19 inhibition. Journal of Drug Delivery Science and Technology, 2020; 60:102046. https://doi.org/10.1016/j.jddst.2020.102046

37. Drucker DJ. Advances in oral peptide therapeutics. Nature reviews Drug discovery. 2020 Apr; 19(4):277-89.

38. Kurakula, M., Sobahi, T. R., El-Helw, A., \& Abdelaal, M. Y Development and validation of a RP-HPLC method for assay of atorvastatin and its application in dissolution studies on thermosensitive hydrogel-based nanocrystals. Tropical Journal of Pharmaceutical Research, 2014; 13(10):1681-1687. https://doi.org/10.4314/tjpr.v13i10.16

39. Fopase R, Bhardwaj A, Yadav VS, Pandey LM. Engineered drug delivery systems: insights of biointerface. InBiointerface Engineering: Prospects in Medical Diagnostics and Drug Delivery 2020 (pp. 1-30). Springer, Singapore.

40. Kirkby M, Hutton AR, Donnelly RF. Microneedle Mediated Transdermal Delivery of Protein, Peptide and Antibody Based Therapeutics: Current Status and Future Considerations. Pharmaceutical Research. 2020; 37(6).

41. Kurakula, M., Srinivas, C., Kasturi, N., \& Diwan, P. V. Formulation and Evaluation of Prednisolone Proliposomal Gel for Effective Topical Pharmacotherapy. International Journal of Pharmaceutical Sciences and Drug Research, 2012; 4(1):35.
42. Vedadghavami A, Zhang C, Bajpayee AG. Overcoming negatively charged tissue barriers: Drug delivery using cationic peptides and proteins. Nano today. 2020 Oct 1; 34:100898.

43. Ng YM, Mat Yusuf SN, Chiu HI, Lim V. Redox-Sensitive Linear and Cross-Linked Cystamine-Based Polymers for ColonTargeted Drug Delivery: Design, Synthesis, and Characterisation. Pharmaceutics. 2020 May; 12(5):461.

44. Mallesh, K., Pasula, N., \& Kumar Ranjith, C. P. Piroxicam proliposomal gel: a novel approach for tropical delivery. Journal of Pharmacy Research, 2012; 5(3):1755-1763.

45. Kurakula M, Mohd AB, Rao PA, Diwan PV. Estimation of piroxicam in proliposomal formulation using RPHPLC method. Int. J. Chem. Anal. Sci. 2011; 2:1193. 2011; 1196.

46. Kurakula M, Naveen NR. Prospection of recent chitosan biomedical trends: Evidence from patent analysis (2009-2020). International Journal of Biological Macromolecules. 2020 Oct 15.

47. Hartl N, Adams F, Merkel OM. From Adsorption to Covalent Bonding: Apolipoprotein E Functionalization of Polymeric Nanoparticles for Drug Delivery Across the Blood-Brain Barrier. Advanced Therapeutics. 2020:2000092.

48. Venkatesh, M., \& Mallesh, K. Self-Nano Emulsifying Drug Delivery System (SNEDDS) for Oral Delivery of AtorvastatinFormulation and Bioavailability Studies. Journal of Drug Delivery and Therapeutics, 2013; 3(3):131-140. https://doi.org/10.22270/jddt.v3i3.517

49. Kanazawa T, Taki H, Okada H. Nose-to-brain drug delivery system with ligand/cell-penetrating peptide-modified polymeric nano-micelles for intracerebral gliomas. European Journal of Pharmaceutics and Biopharmaceutics. 2020 May 5.

50. Kurakula M, Mohd AB, Samhuidrom AP, Diwan PV. Estimation of prednisolone in proliposomal formulation using RP HPLC method. Int. J. Res. Pharm. Biomed. Sci. 2011; 2:663.

51. Lu J, Wang H, Tian Z, Hou Y, Lu H. Cryopolymerization of 1, 2Dithiolanes for the Facile and Reversible Grafting-from Synthesis of Protein-Polydisulfide Conjugates. Journal of the American Chemical Society. 2020 Jan 13; 142(3):1217-21.

52. Xie D, Wang F, Xiang Y, Huang Y. Enhanced nuclear delivery of H1-S6A, F8A peptide by NrTP6-modified polymeric platform. International Journal of Pharmaceutics. 2020 Mar 12:119224.

53. Murali, V. P., Fujiwara, T., Gallop, C., Wang, Y., Wilson, J. A., Atwill, M. T., Kurakula, M., \& Bumgardner, J. D. Modified electrospun chitosan membranes for controlled release of simvastatin. International Journal of Pharmaceutics, 2020; 584:119438. https://doi.org/10.1016/j.ijpharm.2020.119438

54. Salameh JW, Zhou L, Ward SM, Santa Chalarca CF, Emrick T, Figueiredo ML. Polymer-mediated gene therapy: Recent advances and merging of delivery techniques. Wiley Interdisciplinary Reviews: Nanomedicine and Nanobiotechnology. 2020 Mar; 12(2):e1598.

55. Chen S, Wu L, Ren J, Bemmer VL, Zajicek R, Chen R. Comb-Like Pseudopeptides Enable Very Rapid and Efficient Intracellular Trehalose Delivery for Enhanced Cryopreservation of Erythrocytes. ACS Applied Materials \& Interfaces. 2020 Jun 4.

56. Shen W, Wang R, Fan Q, Gao X, Wang H, Shen Y, Li Y, Cheng Y. Natural Polyphenol Inspired Polycatechols for Efficient siRNA Delivery. CCS Chemistry. 2020 Mar 9:146-57.

57. Gui L, Zhang XH, Qiao ZY, Wang H. Cell-Penetrating Peptides and Polymers for Improved Drug Delivery. ChemNanoMat.

58. Naguib, Ghada Hussein, Al-Hazmi, F. E., Kurakula, M., Abdulaziz Al-Dharrab, A., Mohamed Hosny, K., Mohammed Alkhalidi, H., Tharwat Hamed, M., Habiballah Hassan, A., Al-Mohammadi, A. M., Mohamed Alnowaiser, A., \& Henry Pashley, D. Zein coated zinc oxide nanoparticles: Fabrication and antimicrobial evaluation as dental aid. International Journal of Pharmacology, 2018; https://doi.org/10.3923/ijp.2018.1051.1059

59. Mainini F, Eccles MR. Lipid and Polymer-Based Nanoparticle siRNA Delivery Systems for Cancer Therapy. Molecules. 2020 Jan; 25(11):2692.

60. Shakeri S, Ashrafizadeh M, Zarrabi A, Roghanian R, Afshar EG, Pardakhty A, Mohammadinejad R, Kumar A, Thakur VK. Multifunctional polymeric nanoplatforms for brain diseases diagnosis, therapy and theranostics. Biomedicines. 2020 Jan; 8(1):13.

61. Kovács AN, Varga N, Juhász Á, Csapó E. Serum proteinhyaluronic acid complex nanocarriers: Structural characterisation and encapsulation possibilities. Carbohydrate 
Polymers. 2020 Sep 7; 251:117047.

62. Naveen, N. R., Gopinath, C., \& Kurakula, M. Okra-thioglycolic acid conjugate-synthesis, characterization, and evaluation as a mucoadhesive polymer. Processes, 2020; 8(3):316. https://doi.org/10.3390/pr8030316

63. Zhang C, Yang L, Wan F, Bera H, Cun D, Rantanen J, Yang M. Quality by Design thinking in the development of long-acting injectable PLGA/PLA-based microspheres for peptide and protein drug delivery. International Journal of Pharmaceutics. 2020 May 19:119441.

64. Uddin S. Peptide Drug/Device Combinations. In Development of Biopharmaceutical Drug-Device Products 2020 (pp. 613-637). Springer, Cham.

65. Raghavendra Naveen, N., Kurakula, M., \& Gowthami, B. Process optimization by response surface methodology for preparation and evaluation of methotrexate loaded chitosan nanoparticles. Materials Today: Proceedings. 2020. https://doi.org/10.1016/j.matpr.2020.01.491

66. Wang W, Mattoussi H. Engineering the Bio-Nano Interface Using a Multifunctional Coordinating Polymer Coating. Accounts of Chemical Research. 2020 May 19.

67. Leigh T, Fernandez-Trillo P. Helical polymers for biological and medical applications. Nature Reviews Chemistry. 2020 May 5:120.

68. Vanitasagar, S., Srinivas, C., Subhashini, N. J. P., \& Mallesh, K. Solid dispersion-a comparative study on the dissolution rate of aceclofenac. International Journal of Pharmacy and Pharmaceutical Sciences, 2012; 4(SUPPL.3):274-278.
69. Ibeanu N, Egbu R, Onyekuru L, Javaheri H, Khaw PT, Williams GR, Brocchini S, Awwad S. Injectables and Depots to Prolong Drug Action of Proteins and Peptides. Pharmaceutics. 2020 Oct; 12(10):999.

70. Acosta S, Ye Z, Aparicio C, Alonso M, Rodríguez-Cabello JC. Dual Self-Assembled Nanostructures from Intrinsically Disordered Protein Polymers with LCST Behavior and Antimicrobial Peptides. Biomacromolecules. 2020 Jul 30; 21(10):4043-52.

71. Gradinati V, Baruffaldi F, Abbaraju S, Laudenbach M, Amin R, Gilger B, Velagaleti P, Pravetoni M. Polymer-mediated delivery of vaccines to treat opioid use disorders and to reduce opioidinduced toxicity. Vaccine. 2020 May 19.

72. Chen C, Richter F, Guerrero-Sanchez C, Traeger A, Schubert US, Feng A, Thang SH. Cell-Penetrating, Peptide-Based RAFT Agent for Constructing Penetration Enhancers. ACS Macro Letters. 2020 Feb 4; 9(2):260-5.

73. Lin JL, Wang ZK, Xu ZY, Wei L, Zhang YC, Wang H, Zhang DW, Zhou W, Zhang YB, Liu Y, Li ZT. Water-Soluble Flexible Organic Frameworks That Include and Deliver Proteins. Journal of the American Chemical Society. 2020 Feb 3; 142(7):3577-82.

74. Meyer CE, Abram SL, Craciun I, Palivan CG. Biomoleculepolymer hybrid compartments: combining the best of both worlds. Physical Chemistry Chemical Physics. 2020.

75. Garg C, Priyam A, Kumar P, Sharma AK, Gupta A. In vitro assessment of core-shell micellar nanostructures of amphiphilic cationic polymer-peptide conjugates as efficient gene and drug carriers. Journal of Pharmaceutical Sciences. 2020 May 28. 